\title{
QUALIDADE DOS SERVIÇOS EM UMA REDE EDUCACIONAL: RELAÇÃO ENTRE EXPECTATIVA E PERCEPÇÃO
}

\author{
Sandro Ergang \\ Leoni Pentiado Godoy \\ Daniel Benitti Lorenzett ${ }^{3}$ \\ Tais Pentiado Godoy ${ }^{4}$ \\ Cláudia Bach Rizzatti 5 \\ Edio Patric Guarienti ${ }^{6}$ \\ Julio Cezar Mairesse Siluk
}

\begin{abstract}
Resumo: Estudos indicam que o estudante, no momento da decisão por uma instituição ou outra, leva em consideração a vivência e o conhecimento mediante pesquisas com amigos e conhecidos. Tornar o estudante divulgador em potencial requer esforço em marketing de relacionamento. A área de qualidade em serviços aponta a SERVQUAL como ferramenta capaz de proporcionar diagnóstico preciso sobre expectativas e percepçóes acerca dos serviços educacionais. Com base nas competências apresentadas, utilizou-se uma amostra de 383 estudantes, de cinco instituiçóes de ensino superior, de uma rede educacional (RS), para verificar e comprovar vantagens e deficiências competitivas, possibilitando a concentração de esforços nesses pontos críticos. Os resultados obtidos, por meio deste instrumento, poderão servir como indicador significativo para gestores de instituições de ensino, que pretendam identificar áreas de melhoria necessárias no pacote do serviço educacional, e aos investigadores que procurem instrumento de mensuraçáo da qualidade em serviços.
\end{abstract}

Palavras-chave: Expectativa e percepçôes. Instituiçôes de ensino. Dimensôes da qualidade

Abstract: Studies indicate that the student at the time of the decision by an institution or another takes into account the experience and knowledge through research with friends and acquaintances. Making the student potential in spreader requires effort on relationship marketing. The area of quality in service points the SERVQUAL as a tool capable of providing accurate diagnosis on expectations and perceptions of educational services. Based on the competencies presented using a sample of 383 students from five institutions of higher education in an Educational Network (RS), to verify and prove competitive strengths and weaknesses, allowing the concentration of efforts on these critical points. The results of this instrument may serve as a significant indicator for managers of educational institutions that seek to identify areas of improvement needed in the educational service package and researchers looking for an instrument to measure quality in services.

Keywords: Expectations and Perceptions. Educational institutions. Dimensions of quality

1 Mestre em Engenharia de Produção pela Universidade Federal de Santa Maria (UFSM), Programa de Pós-Graduação em Engenharia de Produção. E-mail: ergang@setrem.com.br

2 Prof. ${ }^{a}$ Dr. ${ }^{a}$ do Programa de Pós-Graduação em Engenharia de Produçáo da Universidade Federal de Santa Maria (UFSM). E-mail: leoni_godoy@yahoo.com.br

3 Mestrando em Engenharia de Produção pela Universidade Federal de Santa Maria (UFSM), Programa de Pós-Graduação em Engenharia de Produção. E-mail: dlorenzett@gmail.com

4 Mestranda em Engenharia de Produção pela Universidade Federal de Santa Maria (UFSM), Programa de Pós-Graduação em Engenharia de Produção. E-mail: taispentiado@yahoo.com.br

5 Mestranda em Engenharia de Produção pela Universidade Federal de Santa Maria (UFSM), Programa de Pós-Graduação em Engenharia de Produção. E-mail: claudiabach@hotmail.com

6 Mestrando em Engenharia de Produção pela Universidade Federal de Santa Maria (UFSM), Programa de Pós-Graduação em Engenharia de Produção. E-mail: edioguarienti@yahoo.com.br

7 Prof. Dr. do Programa de Pós-Graduação em Engenharia de Produção da Universidade Federal de Santa Maria (UFSM). E-mail: jsiluk@ufsm.br 


\section{INTRODUÇÃO}

Analisando a competitividade, no cenário do ensino superior no Brasil, é possível observar a preocupação, cada vez maior, das organizaçóes, principalmente das instituiçôes de ensino privado, em adotar uma nova postura. Para isso, é necessário apresentar propostas de ensino e gestáo que atendam aos anseios da sociedade e envolvam, como consequência, os dirigentes, o corpo docente, os técnicos administrativos e serviços de apoio.

Neste caso, a avaliação feita, pelo próprio estudante, serve de termômetro ou de parâmetro para identificar a intensidade e a qualidade no relacionamento entre as partes envolvidas.

Assim, em um cenário desenvolvido mediante pesquisa diagnóstica, visualiza-se a necessidade de adquirir ou desenvolver mecanismos de gerenciamento e controle das relaçóes com o consumidor de serviços educacionais. O Customer Relationship Management (CRM), em outras palavras, a Gestão do Marketing de Relacionamento possibilita o controle e gerenciamento das informaçôes relacionadas ao consumidor.

O presente estudo não tem a pretensão de enfocar a análise da qualidade dos processos educacionais, ou até mesmo a qualidade em educação, mas analisar, de forma ampla e genérica, aspectos como: infra-estrutura, atendimento, receptividade, confiabilidade, e segurança.

Também pretende-se mostrar como esses aspectos são percebidos pelo estudante, quais suas expectativas com relaçáo eles, bem como, a percepção dos executores destas atividades, gestores, professores e funcionários em relação a esses mesmos aspectos.

Não é pretensão avaliar os aspectos pedagógicos, sendo frequentemente utilizada a expressão "cliente", para se referir aos potenciais estudantes (prospect's), outras vezes será utilizada a expressão "estudante", para referir-se aos acadêmicos inseridos nas diferentes instituições.

Como objetivo do presente trabalho, tem-se a mensuração da qualidade em serviços educacionais, a fim de identificar elementos que possam servir de suporte ao gerenciamento do relacionamento com o cliente, e também tornar genérica aos cursos superiores da Rede de Educação estudada, de forma que esta possa oferecer seus produtos, com a devida orientação para o marketing de relacionamento, transformando estas informaçôes em vantagem competitiva.

Dessa forma, pretende-se, com o estudo, proporcionar um diagnóstico que permita identificar os elementos facilitadores, para o desenvolvimento da gestáo dos processos de relacionamento entre o fornecedor e o usuário de serviços educacionais, promovendo a melhoria contínua das organizaçôes e de seus colaboradores.

\section{QUALIDADE EM SERVIÇOS}

Quando exploradas as características dos serviços, quanto a sua natureza, (intangibilidade, perecibilidade, heterogeneidade ou variabilidade, e inseparabilidade ou simultaneidade), com certa frequência argumenta-se que, principalmente pela simultaneidade, uma das quatro principais características citadas, em que o serviço é consumido ao mesmo tempo em que é produzido, faz-se necessário que este seja produzido com qualidade, e que esta seja perceptível.

Os serviços, atualmente, são utilizados para criar valor junto à indústria, desempenhando papel importante ao adicionar valor aos produtos (Vandermerwe, 1993; Bryson, 2010).

O termo serviço descreve um conjunto heterogêneo de atividades, incluindo negócios e serviços profissionais, finanças e serviços ao consumidor (Love et al., 2010). Portanto, pode-se dizer que, a qualidade percebida é influenciada pelas expectativas e percepçóes dos clientes. $\mathrm{O}$ consumidor do serviço ou produto analisa a qualidade, provocando o nível de satisfação, que, por sua vez, pode levar à retenção e à lealdade de clientes.

Blackwell et al. (2005), afirmam que a satisfação trata do resultado de uma comparação de expectativas (pré-compra) com os resultados reais (percepção). Alguns processos de desconfirmação da expectativa determinam a percepção do consumidor diante da compra. A satisfação ou não, do cliente, com a qualidade do serviço, pode ser mensurada por meio das expectativas e percepçóes do cliente que recebe o serviço.

Esse mesmo autores afirmam a existência de três possibilidades de ocorrência da desconfirmação:

1. Desconfirmação Positiva: o desempenho do produto sendo melhor que o esperado, o cliente ficará satisfeito com a compra. 
a) Confirmação Simples: o desempenho do produto equivale às expectativas, o cliente terá uma posição neutra diante do produto.

b) Desconfirmação Negativa: sendo o desempenho pior do que o esperado, as necessidades e expectativas não sendo atendidas, geram insatisfação.

Ainda segundo Blackwell et al. (2005), a lealdade do cliente, baseada em satisfação genuína e contínua, é um dos maiores ativos que uma empresa pode adquirir. Para Gianesi e Corrêa (1996), identificar os critérios, pelos quais os clientes avaliam os serviços, é uma maneira de melhor compreender suas expectativas.

Parasuraman et al. (1990, 1991), tomando como base as dez dimensóes da qualidade dos serviços, desenvolveram um questionário chamado de escala SERVQUAL, utilizando as diversas ocorrências de satisfação por meio do modelo Gap. Segundo Stefano (2009), foi realizado um refinamento deste instrumento e chegou-se a um resultado de cinco dimensóes da qualidade, totalizando 22 questôes.

A escala SERVQUAL tem sido amplamente difundida e aceita como método para a avaliação da qualidade em serviços, sendo aplicada em estudos nas mais diferentes áreas do setor serviços (Babakus e Mangold, 1992; Newman, 2001; Lai et al., 2007; Ahmed e Shoeb, 2009; Butt e Run, 2010).

As cinco dimensóes da qualidade, resultantes do refinamento da escala, foram as seguintes: confiabilidade, responsividade, confiança, empatia e tangibilidade (Stefano, 2009).

Inseridos em cada dimensão, encontram-se vários itens medidos em uma escala de cinco ou sete pontos, com os extremos de "concordo inteiramente" a "discordo inteiramente". Para consolidar, de forma geral, o questionário inclui uma avaliação de serviço. Zeithaml, Parasuraman e Berry criaram esse instrumento com o intuito de avaliar a percepçáo dos clientes a respeito da qualidade dos serviços (Gianesi e Corrêa, 1996).

A escala SERVQUAL é um instrumento resumido de escala múltipla, com um alto nível de confiabilidade e validade, que as organizações poderão utilizar para melhor compreenderem as expectativas e percepçóes que os clientes tenham a respeito de um serviço.
Entre os grandes problemas que as organizaçôes enfrentam, um deles é identificar qual o perfil dos seus clientes, quais suas preferências e de que forma a organização pode atuar para buscar sua satisfação.

Além disso, as organizaçóes necessitam buscar formas alternativas de atrair o cliente, por meio de promoçóes e ofertas. Hoje, um dos grandes diferenciais para atraçáo de clientes, pode ser a utilizaçáo do relacionamento direto, personalizado e centrado na oferta de produtos e serviços, elaborados especificamente para cada cliente ou grupo de clientes.

Para tanto, pode-se utilizar a metodologia Customer Relantionship Management (CRM), ou gerenciamento do relacionamento com o cliente, que possibilita gerenciar os dados disponíveis dos clientes, gerados a partir do relacionamento, de forma personalizada, com o intuito de atender suas expectativas, até mesmo as mais ocultas (Azevedo et al., 2006; Blery e Michalakopoulos, 2006; Kimiloglu e Zarali, 2009).

Segundo Azevedo et al. (2006), uma vez obtidas as informaçóes, pode-se proceder a determinação das estratégias a serem utilizadas, para atender às necessidades identificadas, permitindo que a entidade possa integrar todos os pontos de contato com o cliente. Assim, esse gerenciamento possibilita uma troca de informaçóes mais dinâmica e facilitada para ambas as partes.

\section{GESTÁO DO RELACIONAMENTO COM O CLIENTE}

Dentre os grandes problemas que as organizaçóes enfrentam, destaca-se a identificação do perfil dos clientes, suas preferências e de que forma a organização poderá atuar para buscar sua satisfação. Além disso, as organizaçóes necessitam buscar formas alternativas para atrair o cliente, seja através de promoções e/ou ofertas.

Plata (2003) e Swift (2001) mostram que o gerenciamento do relacionamento com o cliente é um propósito para transformar o processo de negócios, com o objetivo de conservar e conseguir mais clientes. Os autores, ainda, consideram esse gerenciamento, uma ferramenta administrativa para entender e influenciar o comportamento dos clientes, por meio de comunicaçôes significativas para melhorar a retençáo e lealdade da clientela, que influi diretamente na lucratividade. 
Hoje, um dos grandes diferenciais, para atraçáo de clientes, pode ser a utilização do relacionamento direto, personalizado e centrado na oferta de produtos e serviços, elaborados especificamente para cada cliente ou grupo de clientes. Para tanto, as organizaçóes precisam identificar quais são os clientes, quais suas necessidades e de que forma, ela pode satisfazê-las.

As organizaçóes devem agir, por meio do marketing direto, oferecendo produtos e serviços diferenciados, com objetivos definidos, ou seja, a satisfaçáo do cliente, que produzirá aumento de rentabilidade para a organização.

Com a utilizaçáo de uma metodologia Customer Relantionship Management (CRM) torna-se possível gerenciar os dados disponíveis dos clientes, gerados a partir do relacionamento, utilizando-se de comunicação direta com o cliente, de forma personalizada, com o intuito de atender suas expectativas, até mesmo as mais ocultas.

Uma base de dados, contendo informaçóes precisas sobre essas expectativas, poderá ser utilizada para pesquisa de comportamento, planejamento estratégico, desenvolvimento de produtos, estudos demográficos, identificação e retenção dos melhores clientes e programas de marketing direto de massa ou dirigido.

Com o desenvolvimento de uma base de informaçôes, uma Instituição de Ensino Superior, poderá expandir sua visão, sobre a expectativa dos estudantes com interesse no ensino superior, possibilitando, assim, às organizaçôes, segmentarem melhor o seu mercado, identificarem seu público alvo e atuarem de forma pró-ativa, antecipando-se às necessidades dos clientes, no desenvolvimento de suas açôes de marketing.

Uma metodologia CRM não nasce pronta, é adaptada à necessidade da organização. A base de dados, inicialmente, é desenvolvida para atender às necessidades de informaçóes que cada instituição julgue importante. Entretanto, um sistema de gerenciamento de dados, por si só, não resolve os problemas da instituição.

Com o passar do tempo, e o amadurecimento do CRM e das relaçóes com os clientes, a instituição tende a visualizar novas prioridades, tanto de necessidade de dados quanto de obtenção de informaçôes. Para atender a essa necessidade, é imprescindível que a base de dados seja flexível, permitindo alteraçóes de acordo com a necessidade das instituiçôes.
Com a utilização de um sistema de gerenciamento de informaçóes (CRM), a empresa conseguirá identificar quem são seus clientes, qual seu perfil e quais suas necessidades e, após análise, poderá atuar, de forma efetiva, oferecendo soluções de satisfação.

De nada adianta as organizações identificarem quem são seus clientes, quais são suas necessidades e de que forma poderá atendê-las, se não forem implementadas açóes para resolver essas questôes. A ação pode ser feita por meio do $m a-$ rketing de relacionamento, que proporciona uma atuação direta com os clientes, de forma personalizada e individual, valorizando-os e proporcionando-lhes maior satisfação, por meio da identificação e atendimento de suas necessidades.

A ferramenta do CRM deve ser utilizada para viabilizar a prática do que já vem sendo proposto, como a resposta aos desafios do novo século. Isso significa reinventar a forma de se comunicar e administrar o relacionamento do cliente (Bretzke, 2000, p. 202).

Enfim, Customer Relationship Management pode ser caracterizado como um sistema eficiente, prático e que responde às necessidades de gerenciamento de dados e obtenção de informações, desde que as instituiçôes tenham seu foco voltado ao relacionamento com o cliente, pois uma da forma altamente eficiente de disseminar a cultura organizacional e comunicar que a instituição trabalha com qualidade, é por meio dos clientes.

São os clientes que, em conversas informais e pessoais, acabam por se constituírem promotores, ampliando a comunicação institucional.

\section{MARKETING NA EDUCAÇÃO}

À medida que o tempo passa, escolas, faculdades, universidades e outras instituiçóes educacionais reconhecem, cada vez mais, que enfrentam problemas de marketing. $\mathrm{O}$ decréscimo do número de alunos potenciais, matrículas, contribuiçóes e outros recursos para enfrentar os custos, bem como o crescente aumento da concorrência e a abertura de novos cursos, demonstram a dependência dessas instituições em relação ao mercado que atendem.

Todas as instituiçôes enfrentam a tarefa de definir quem está em seu mercado. Uma faculdade percebe que nem todos os jovens, que estáo no mercado, pretendem obter formação universitária. 
Entre aqueles que desejem esta formação, alguns não estão interessados em matricular-se nesta ou naquela faculdade, já escolheram uma terceira.

Outros, ainda pretendem matricular-se em um curso profissionalizante, que, de modo geral, têm criado uma espécie de atalho para o mercado de trabalho, principalmente com desenvolvimento específico em determinado segmento com carência de mão de obra especializada. Todavia, cada instituição deve distinguir-se entre seus consumidores potenciais.

Considerando a afirmativa de Kotler e Fox (1994, p.188), "o mercado de uma instituição depende do que ela tem a oferecer e quanto mais precisamente definirmos a oferta, mais cuidadosamente poderemos determinar as fronteiras e o tamanho do mercado".

As instituiçôes educacionais se utilizam de várias e diferentes formas e técnicas de marketing, porém algumas universidades e faculdades estão começando a aplicar ativamente, e cada vez com mais intensidade, ideias criativas e eficientes de marketing, enquanto outras tantas estão ainda se conscientizando ou se questionando sobre o que o marketing pode oferecer.

O mais intrigante, nesse aspecto, é ser possível observar, em algumas escolas, principalmente aquelas que, de modo geral, trabalham em áreas de Gestão ou áreas afins, igualmente ignoram as técnicas de marketing nas suas gestôes, e se dizem na vanguarda da informação.

As escolas públicas, de maneira geral, não têm mostrado qualquer interesse em marketing, talvez por estarem sob a gestão do Estado e o custo ao usuário deste tipo de serviço ser muito baixo ou até mesmo gratuito, mas mesmo assim gostariam de obter maior apoio público.

$\mathrm{O}$ ensino superior brasileiro vive um aparente paradoxo, onde existe, por um lado, um crescimento contínuo e significativo da demanda de alunos e, por outro, uma crise especulativa, com excesso de vagas em instituiçóes, diluindo a demanda com poder aquisitivo e forçando a queda nos preços (Cobra e Braga, 2004).

Segundo Cobra e Braga (2004), atualmente, não basta que as IES anunciem sua excelência no ensino, instalaçóes modernas, tradição e corpo docente titulado. Nada disso é visto como diferencial competitivo pelo cliente, mas como pré-requisito mínimo para ocupar um lugar no mercado.
O ponto em que uma instituição educacional se direciona para marketing depende, geralmente, da profundidade de seus problemas de marketing. Instituiçóes que apreciam um mercado vendedor, com abundância de estudantes, tendem a ignorar ou a evitar marketing.

Assim pensavam as faculdades dos anos 60, estendendo-se tal pensamento até hoje, por boa parte das Instituições de Ensino Superior, pois se limitam a fazer o processo seletivo de estudantes por meio de divulgação, ignorando estratégias e técnicas de marketing.

Kotler e Fox (1994, p.24) observam que o Marketing consiste na análise, planejamento, implementação e controle de programas, cuidadosamente formulados, para causar trocas voluntárias de valores com mercado-alvo e alcançar os objetivos institucionais. Os autores comentam que o Marketing envolve a programaçáo das ofertas da instituição, para atender às necessidades e os desejos de mercados-alvo, usando preço, comunicação e distribuição eficaz, para informar, motivar e atender a esses mercados.

Os gestores das organizaçóes educacionais tornaram-se realmente conscientes da necessidade de uma administração de marketing quando seus mercados passaram por mudanças, ou quando de fato a demanda se reprimiu.

Quando estudantes, membros conselheiros, fundos ou outros recursos necessários tornaram-se escassos ou difíceis de atrair, as instituiçóes de ensino começaram a preocupar-se. Neste ponto, em alguns casos, como se observa na mídia nacional sobre instituiçôes de ensino com sérios problemas financeiros promovidos pela queda nas matrículas.

Com a redução do número de matrículas e o surgimento de novos concorrentes essas instituiçóes ficaram mais receptivas a possíveis soluçóes, como marketing, por exemplo. De acordo com Kotler e Fox (1994), a função do Marketing não se limita a atrair matrículas, pois atrair alunos não é o suficiente, é necessário mantê-los. Segundo os autores, é preciso, ainda, conquistar o apoio financeiro de ex-alunos, fundaçóes e outros doadores.

Uma orientação de marketing pressupóe que a principal tarefa da instituição é determinar as necessidades e os desejos dos mercados-alvo, e satisfazê-los por meio de projeto, comunicação, fixação de preço e entrega de programas e serviços apropriados e competitivamente viáveis. 
Churchill e Gilbert (2000, p. 118) complementam: "hoje, a maior parte das organizações usa computadores para ajudá-las a coletar, classificar, armazenar e distribuir informaçóes a serem usadas para tomar decisóes de marketing".

Uma forma popular de sistema computadorizado de informaçôes de marketing é o sistema de apoio às decisôes de marketing (SADM), uma série coordenada de dados, ferramentas de sistema e técnicas com software e hardware de apoio, com os quais a organização reúne e interpreta informaçóes relevantes de empresas e do ambiente, transformando-as em uma base para tomada de decisôes gerenciais (Churchill e Gilbert, 2000).

A maioria dos sistemas de registros internos foi preparada para arquivar dados, não para torná-los úteis. Algumas instituiçóes educacionais têm andado a passos largos para tornarem os dados facilmente acessíveis, via terminais de computador, aos administradores que deles precisarem. Entretanto, em muitas outras instituições, o caminho entre a solicitação e a resposta é tão longo que os administradores desistem de pedi-la, ficando impossibilitados de tomarem decisóes com base em informaçôes atualizadas.

Em consonância, Kotler e Fox (1994, p.76) afirmam que "Sistemas de inteligência de marketing é o conjunto de fontes e procedimentos pelos quais, administradores obtêm informaçóes diárias sobre desenvolvimento no ambiente externo".

Há, nesse contexto, a necessidade de se estabelecer uma conexão de contato com o estudante, obviamente este elo de comunicação será a forma como a instituição ou a organização irá ouvir o que ele tem a dizer sobre o produto, serviço ou relacionamento com a instituição, principalmente quando se trata de instituiçôes de ensino, pois, neste caso, se não houver harmonia no relacionamento, dificilmente haverá satisfação, independente da condição de usuário ou fornecedor deste tipo de serviço. Como destaca Whiteley (1992, p.20), a única forma correta de administrar uma companhia, e a forma mais rentável, consiste em saturá-la com a voz dos clientes.

O setor educacional brasileiro sofre com problemas localizados, de demanda e oferta, o que não é novidade, pois há regiôes onde sobram vagas e outras tantas em que não há escolas. Segundo Cobra e Braga (2004 p. 42), "em marketing educacional é preciso diferenciar-se no mercado, ser líder, pois ser o único há muito tempo deixou de ser um privilégio, as instituições precisam posicionar-se no mercado de modo que sejam únicas, ou pelo menos uma referência em algum aspecto". Ao que parece, "ouvir o cliente" é a palavra de ordem, descobrir quais sáo as suas expectativas e suas percepçóes é o meio, e estreitar relaçôes e "conversar com o estudante" é a estratégia.

\section{ASPECTOS METODOLÓGICOS}

Tendo em vista o caráter desta pesquisa, que pretende abordar as relaçôes da instituição educacional e seus clientes, será utilizado o método dedutivo, por meio de uma abordagem quali-quantitativa, relacionando a fenomenologia e a estatística para compreender e explicar as diversas percepçóes.

Por meio da observação direta extensiva, identificaram-se as seguintes técnicas como sendo as mais indicadas para a investigação: pesquisas de campo; pesquisa bibliográfica; pesquisa documental; e questionário estruturado (SERVQUAL).

De posse dos dados, foram elaboradas tabelas, gráficos, triangulações, validaçôes, comentários e análises dos resultados, para um melhor entendimento do problema e proposição de soluções.

Quanto à amostragem adotada, optou-se, primeiramente, por um procedimento amostral náo probabilístico. A técnica de amostragem que melhor atendeu aos propósitos da pesquisa foi a amostragem por quotas para a escolha dos indivíduos a serem entrevistados. Optou-se, por esta amostragem, pela diversidade encontrada no número de estudantes nas diferentes instituiçóes de ensino pesquisadas. Fórmula utilizada para cálculo da amostra [1]:

$$
\mathrm{n}=\mathrm{Z}^{2} \cdot \mathrm{p} \cdot \mathrm{q} \cdot \mathrm{N} / \mathrm{d}^{2}(\mathrm{~N}-1)+\mathrm{Z}^{2} \cdot \mathrm{p} \cdot \mathrm{q}
$$

\section{Onde:}

$\mathrm{Z}=$ Nível de Confiança; $\mathrm{N}$ = População; $\mathrm{p}$ = estimativa de proporção; $\mathrm{q}=1-\mathrm{p} ;$ e $\mathrm{d}^{2}=$ erro amostral.

Para efeito de cálculo, foi utilizado um grau de confiança de $95 \%$ e uma margem de erro amostral de 5\%, para uma populaçáo de 1.792 estudantes matriculados nos quinze cursos das cinco instituiçôes, da rede educacional objeto de estudo.

Aplicando-se a fórmula, resulta em uma amostra de 317 estudantes que foram pesquisa- 
dos, distribuídos proporcionalmente pela sua representação no total de alunos do curso e da Instituição.

Os dados foram tratados predominantemente de forma descritiva, com a utilizaçáo de técnicas qualitativas e quantitativas. Portanto, a análise documental foi utilizada para interpretação dos dados secundários e técnicas estatísticas foram empregadas na análise dos dados primários obtidos por meio da aplicaçáo de questionários.

Para testar a metodologia em um caso real, o presente estudo foi realizado em 2007, em cinco instituiçóes de ensino superior integrantes de uma Rede de Educaçáo localizadas no Estado do Rio Grande do Sul. A pesquisa aplicada foi apresentada em dois formulários, sendo o primeiro para avaliar as expectativas sobre serviços educacionais, na seção da direita, e um mínimo adequado para este serviço na seção da esquerda, obedecendo este padrão para as 22 questôes consideradas a partir da metodologia SERVQUAL.

O segundo formulário obedece aos mesmos critérios, entretanto tem a pretensão de avaliar a percepção acerca dos serviços e igualmente um mínimo adequado para estes serviços, seguindo a mesma estrutura anterior. Antes da aplicação do instrumento efetuou-se uma explicação oral, orientando aos respondentes que não iniciassem se acaso permanecessem dúvidas.

No total foram pesquisados 387 (trezentos e oitenta e sete) estudantes, totalizando desta forma 774 (setecentos e setenta e quatro) formulários, destes foi necessário excluir os formulários de quatro (04) entrevistados, por incoerência das respostas, mantendo deste modo, 383 (trezentos e oitenta e três) respondentes.

Definiu-se uma escala de mensuração entre 1 (mínimo) e 9 (máximo) em um primeiro formulário, em um segundo seria utilizado novamente as duas seçóes onde o respondente através da mesma escala avaliaria novamente um mínimo adequado e na segunda seção o serviço percebido ou prestado pela IES.

A intencionalidade ao propor duas colunas para avaliar o serviço mínimo adequado, era identificar se haveriam diferenças ao atribuir um mínimo adequado quando o respondente avalia o serviço desejado do serviço percebido.

Após a conclusão da digitação dos 383 formulários de cada planilha, totalizando deste modo 766 formulários, foram apurados as médias de cada questão de ambas as planilhas. Posteriormente, foi criada uma terceira planilha, para onde foram exportados os dados (média de todos formulários) de cada questão abordada, obedecendo o mesmo critério do formulário, uma linha para cada questáo e uma coluna para cada seção (SM $\mathrm{SD} / \mathrm{SM}-\mathrm{SP}$ ).

Entre estas colunas inseriu-se uma nova coluna a fim de encontrar o GAP ou lacuna entre as seçóes inserindo uma subtraçáo entre as seções, e mais duas colunas para encontrar o GAP do Serviço Mínimo de ambos os formulários, bem como do GAP do Serviço Desejado e do Serviço Percebido.

Como uma das premissas da metodologia SERVQUAL, é a de elaborar as questóes a partir das dimensôes da qualidade, Tangíveis, Confiabilidade, Responsividade, Segurança e Empatia. As questóes aplicadas foram codificadas e assim separadas: as questóes de 1 a 4 relacionavam-se a dimensão dos Tangíveis, de 5 a 9 Confiabilidade, de 10 a 14 Responsividade, de 15 a 18 Segurança e 19 a 22 relacionadas a Empatia.

Tabuladas as questóes foi necessário verificar o coeficiente de correlaçáo por meio do alfa de Cronbach (1990), para confirmar a confiabilidade da pesquisa. Para aplicação do coeficiente de correlaçáo do alfa de Cronbach (1990), agruparam-se as questóes por afinidades, seguindo o critério da dimensão como afinidade.

Foram separadas as seçôes do serviço desejado e do mínimo adequado, agrupando as quatro questóes relacionadas aos aspectos Tangíveis, deste modo há como resultado quatro colunas relativas às questôes 1, 2, 3 e 4, da seção serviço desejado.

Primeiramente, insere-se uma fórmula somando os quatro resultados excluindo-se o primeiro, na segunda coluna o mesmo procedimento excluindo-se a segunda deste modo até a quarta. Este procedimento foi estendido a todos os formulários.

O passo seguinte foi correlacionar uma coluna com a outra, da seguinte forma: a primeira coluna com os resultados obtidos com a operaçáo anterior com a coluna da primeira questáo, utilizando a função de correlação do Excel, e repetindo a operação para as quatro colunas, e ao final produzindo a média das correlaçóes resultantes, para aplicação da fórmula do coeficiente de Cronbach (1990). Fórmula do coeficiente de Cronbach [2]: 


$$
\alpha=\frac{r k}{1+(k-1) r}
$$

Onde:

$r=$ média das correlaçôes das respostas a cada item, com a soma dos demais itens.

$k=$ número de itens sobre apenas 1 tópico.

Deste modo, aplicou-se a fórmula, a partir da média encontrada na operação anterior $(r)$ e multiplicado pelo número de itens sobre apenas 1 tópico que no caso eram as quatro colunas, entáo $k=4$, o resultado desta operaçáo foi dividido pelo resultado da operação que segue 1 mais $k$ (4) menos 1, multiplicado pela média encontrada das colunas $(r)$.

O resultado desta fórmula apresenta um número (coeficiente), com valores de no máximo 1. E podem ser analisados da seguinte forma, coeficientes com valores entre 0,80 e 1,00 possuem alto grau de correlação, entre 0,60 e 0,79 grau de correlação, de aceitável a bom de acordo com o resultado encontrado, quanto maior melhor. E abaixo de 0,60 sugere-se verificar as questóes formuladas ou questionários que possam ter sido respondidos sem a exata compreensão da sua proposta, ou resposta fora de padrão.

Estas operaçóes foram repetidas com todas as questôes e seçôes até que se obtivesse o coeficiente de correlação de todas as questóes e formulários. Todos os coeficientes encontrados foram satisfatórios e à exceção de um que obteve média 0,79 . Todos os demais obtiveram coeficientes de correlaçáo acima de 0,80 .

\section{APRESENTAÇÃO E ANÁLISE DOS RESULTADOS}

A análise dos resultados da pesquisa foi planejada para ser abordada primeiramente, para o público que utiliza estes serviços com status de "cliente", os estudantes. Os resultados apresentam-se ordenados inicialmente em uma abordagem mais ampla, passando por análises mais específicas, investigando características que possam ser utilizadas como oportunidades de melhoria e até mesmo como vantagens competitivas.

Os dados aqui apresentados foram tratados da seguinte forma, as respostas dos 383 entrevistados foram separadas por questóes, considerando-se as variáveis, mínimo adequado, serviço desejado e serviço percebido. Após separados e identificados efetuou-se uma média aritmética do total de questionários divididos por questão e posteriormente agrupados por dimensão da qualidade em serviços.

Obtendo as médias individuais de cada questão e subdivididas por seção, estes resultados foram agrupados e identificados de acordo com cada seçáo correspondente em uma tabela para facilitar a análise e condensar estes resultados. A partir disto foi possível realizar o cruzamento das seçôes para identificar os GAP's de cada seção, identificados questão à questão, proporcionando ainda a identificação dos $G A P$ 's por dimensôes da qualidade, uma vez que estas foram codificadas para facilitar a visualização.

Esta metodologia de análise foi utilizada em praticamente todas as análises da pesquisa, a estruturação dos dados pode ser visualizada na Tabela 1 , onde são apresentadas as representaçôes numéricas da pesquisa. Para facilitar a visualização da representação dos dados foram reproduzidos gráficos, que seguem um padrão de apresentação, para facilitar o acompanhamento da análise dos resultados e das variaçóes a partir dos diferentes cenários.

A Tabela 1 apresenta os resultados gerais da pesquisa feita com todos entrevistados sem distinção por IES ou região. Para melhor compreensão da Tabela 1, têm-se as linhas horizontais numeradas de 1 a 22 correspondendo às questóes aplicadas no questionário construído a partir da metodologia SERVQUAL, e para facilitar a identificação, as questôes foram sintetizadas para efeito de análise. $\mathrm{Na}$ coluna "Dimensóes" apresenta-se a codificação das questôes para correlacionar as dimensóes da qualidade em serviços. Na sequência à direita aparece a coluna "mínimo adequado" identificando um mínimo adequado para o serviço desejado.

Ao lado aparece a coluna $G A P$, que identifica a diferença entre o mínimo adequado e o serviço desejado, ao lado e à direita aparece a coluna identificada como "GAP sm”, que é o resultado da diferença entre os mínimos adequados dos serviços desejados e percebidos. Na sequência aparece novamente uma coluna identificada como "mínimo adequado", no entanto ela identifica o mínimo adequado do serviço percebido, e na última coluna da direita, aparece novamente uma coluna identificando o $G A P$, entre o serviço desejado e o serviço percebido.

$\mathrm{Na}$ coluna da esquerda, a primeira identifica ou agrupa as questóes relacionadas a cada di- 
mensão da qualidade, logo a seguir aparece uma coluna com valores de um novo $G A P$, este por sua vez representa o $G A P$ de cada dimensão, constituído por meio da média aritmética dos $G A P$ 's de cada questáo correlacionada.

$\mathrm{Na}$ última linha de cada coluna aparece uma média aritmética de cada seção avaliada, excetuando-se o resultado dos GAP's que utilizam a subtração entre as seçóes. Observa-se que, a questão que apresenta maior expectativa nos estudantes, é a de número 5, abordando o comprometimento da escola com os estudantes.

Quanto ao cumprimento dos prazos, a média desta questáo relacionada à expectativa representa um valor de 8,52 coincidentemente, também é a questão que apresenta maior $\operatorname{GAP}(1,61)$, ou seja, maior índice de insatisfação com relação ao serviço percebido, em que a média representa um valor de 6,91.
Note que, embora este tenha sido o item mais crítico na avaliação, por apresentar o maior $G A P$, ele não é o item que na percepção dos estudantes tem a menor média entre a coluna do serviço percebido.

Observe a questáo 18 que pretende avaliar se as escolas dão atençáo individual aos estudantes, quanto à percepção obteve-se uma média muito próxima 6,94 , embora esta ainda não seja a mais baixa, mas se comparada com a média do serviço desejado obtém-se uma média de 7,75 resultando em um GAP de 0,81.

Isto mostra que, mesmo a média da percepçáo deste quesito tenha sido baixa esta não se torna relevante, pois, a importância dada pelos estudantes neste item pela média geral é relativamente baixa, entretanto, não significa que seja verdadeiro a todos os campus da Rede Educacional estudada.

Tabela 1: Análise dos serviços educacionais da Rede

\begin{tabular}{|c|c|c|c|c|c|c|c|c|c|c|c|c|}
\hline \multicolumn{4}{|c|}{ Resultados Rede Educacional } & \multirow{2}{*}{$\begin{array}{l}\text { Dimen- } \\
\text { sões }\end{array}$} & \multirow{2}{*}{$\begin{array}{l}\text { Mínimo } \\
\text { Adequado }\end{array}$} & \multirow[b]{2}{*}{ GAP } & \multirow{2}{*}{$\begin{array}{l}\text { Serviço } \\
\text { Desejado }\end{array}$} & \multirow[b]{2}{*}{ GAP sm } & \multirow{2}{*}{$\begin{array}{l}\text { Mínimo } \\
\text { Adequado }\end{array}$} & \multirow[b]{2}{*}{ GAP } & \multirow{2}{*}{$\begin{array}{l}\text { Serviço } \\
\text { Percebido }\end{array}$} & \multirow[b]{2}{*}{ GAP } \\
\hline $\begin{array}{l}\text { Dimen- } \\
\text { sões }\end{array}$ & GAP & & Questão & & & & & & & & & \\
\hline \multirow{4}{*}{ 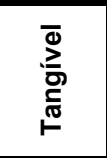 } & \multirow{4}{*}{0,47} & 1 & Equipamentos & $\mathrm{T}$ & 6,91 & 1,57 & 8,49 & 0,03 & 6,94 & 0,18 & 7,12 & 1,37 \\
\hline & & 2 & Instalações físicas & $\mathrm{T}$ & 6,04 & 1,57 & 7,61 & 0,5 & 6,54 & 0,54 & 7,08 & 0,54 \\
\hline & & 3 & Aparência colaboradores & $T$ & 5,87 & 1,23 & 7,1 & 0,64 & 6,51 & 1,01 & 7,52 & $-0,42$ \\
\hline & & 4 & Apresentação dos materiais & $\bar{T}$ & 6,04 & 1,41 & 7,45 & 0,38 & 6,42 & 0,64 & 7,06 & 0,39 \\
\hline \multirow{5}{*}{ 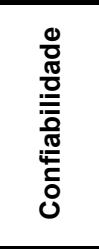 } & \multirow{5}{*}{1,37} & 5 & Cumprimento de prazos & $\bar{C}$ & 7,6 & $\overline{0,92}$ & 8,52 & $-0,57$ & $\overline{7,04}$ & $-0,13$ & 6,91 & $\overline{1,61}$ \\
\hline & & 6 & Compreensão de problemas & C & 6,57 & 1,45 & 8,02 & 0,26 & 6,83 & $-0,24$ & 6,59 & 1,43 \\
\hline & & 7 & $\begin{array}{l}\text { Fazer bem feito da primeira } \\
\text { vez }\end{array}$ & c & 6,77 & 1,35 & 8,11 & 0,03 & 6,8 & $-0,2$ & 6,6 & 1,51 \\
\hline & & 8 & $\begin{array}{l}\text { Fornecimento de serviços no } \\
\text { prazo }\end{array}$ & c & 7,12 & 1,15 & 8,27 & $-0,19$ & 6,93 & 0,04 & 6,97 & 1,3 \\
\hline & & 9 & Atualização de registros & C & 7,08 & 1,1 & 8,18 & $-0,09$ & 6,99 & 0,17 & 7,17 & 1,02 \\
\hline \multirow{4}{*}{ 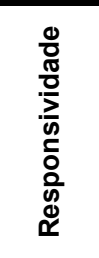 } & \multirow{4}{*}{0,84} & 10 & $\begin{array}{l}\text { Comunicação da realização } \\
\text { dos serv. }\end{array}$ & $\mathrm{R}$ & 6,78 & 1,13 & 7,91 & 0,01 & 6,8 & 0,15 & 6,95 & 0,97 \\
\hline & & 11 & \begin{tabular}{|l|} 
Pronto atendimento pelos \\
colaboradores
\end{tabular} & $\mathrm{R}$ & 6,55 & 1,16 & 7,72 & 0,29 & 6,84 & 0 & 6,84 & 0,88 \\
\hline & & 12 & $\begin{array}{l}\text { Disponibilidade de ajudar os } \\
\text { estudantes }\end{array}$ & $\mathrm{R}$ & 6,83 & 1,02 & 7,85 & 0,18 & 7,01 & $-0,13$ & 6,88 & 0,97 \\
\hline & & 13 & $\begin{array}{l}\text { Disponibilidade } \mathrm{p} / \text { atender os } \\
\text { estudantes }\end{array}$ & $\mathrm{R}$ & 6,11 & 1,37 & 7,49 & 0,62 & 6,74 & 0,2 & 6,93 & 0,55 \\
\hline \multirow{4}{*}{ 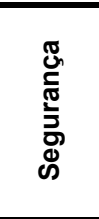 } & \multirow{4}{*}{0,99} & 14 & $\begin{array}{l}\text { Comportamento inspira } \\
\text { confiança }\end{array}$ & s & 7 & 1,14 & 8,14 & 0,01 & 7 & 0 & 7 & 1,13 \\
\hline & & 15 & Segurança em transações & $\mathrm{s}$ & 6,78 & 1,22 & 8 & 0,37 & 7,15 & $-0,08$ & 7,07 & 0,93 \\
\hline & & 16 & Cortesia & $\mathrm{s}$ & 6,74 & 1,34 & 8,08 & 0,3 & 7,03 & 0,05 & 7,08 & 1 \\
\hline & & 17 & $\begin{array}{l}\text { Preparados para responder } \\
\text { dúvidas }\end{array}$ & $S$ & 6,63 & 1,45 & 8,08 & 0,53 & 7,16 & 0,03 & 7,2 & 0,88 \\
\hline \multirow{5}{*}{ 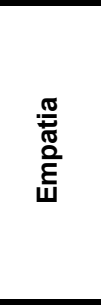 } & \multirow{5}{*}{0,98} & 18 & Atenção individual & $\mathrm{E}$ & 6,22 & 1,53 & 7,75 & 0,7 & 6,92 & 0,03 & 6,94 & 0,81 \\
\hline & & 19 & $\begin{array}{l}\text { Horários de funcionamento } \\
\text { convenientes }\end{array}$ & E & 6,37 & 1,45 & 7,81 & 0,64 & 7,01 & 0,24 & 7,25 & 0,56 \\
\hline & & 20 & $\begin{array}{l}\text { Comunicação adequada com } \\
\text { estudantes }\end{array}$ & E & 6,6 & 1,38 & 7,98 & 0,39 & 6,9 & 0,05 & 7,04 & 0,94 \\
\hline & & 21 & $\begin{array}{l}\text { Comprometimento com os } \\
\text { interesses do estudante }\end{array}$ & E & 6,74 & 1,28 & 8,02 & 0,27 & 7,01 & $-0,25$ & 6,76 & 1,26 \\
\hline & & 22 & $\begin{array}{l}\text { Entendem as necessidades } \\
\text { específicas }\end{array}$ & E & 6,59 & 1,51 & 8,1 & 0,35 & 6,95 & $-0,17$ & 6,77 & 1,33 \\
\hline & & & & & 6,63 & 1,31 & 7,94 & 0,26 & 6,89 & 0,10 & 6,99 & 0,95 \\
\hline
\end{tabular}


Para que seja possível observar melhor o movimento destes resultados e possibilitar a ampliação da análise na Rede Educacional como um todo, é apresentada a seguir a Figura 1, representando graficamente as oscilaçôes da percepção dos entrevistados entre os serviços mínimos apresentados (desejado x percebido). se faz presente, embora esta média de variação ou GAP fique em torno de 0,26.

Este número isoladamente pode não parecer representativo, mas se comparado à média do GAP dos Serviços 0,95 (última coluna da Tabela 1), tem-se uma variação de $27 \%$. Esta representação ajuda a compreender que, dependendo do item que está sendo avaliado, há uma carga

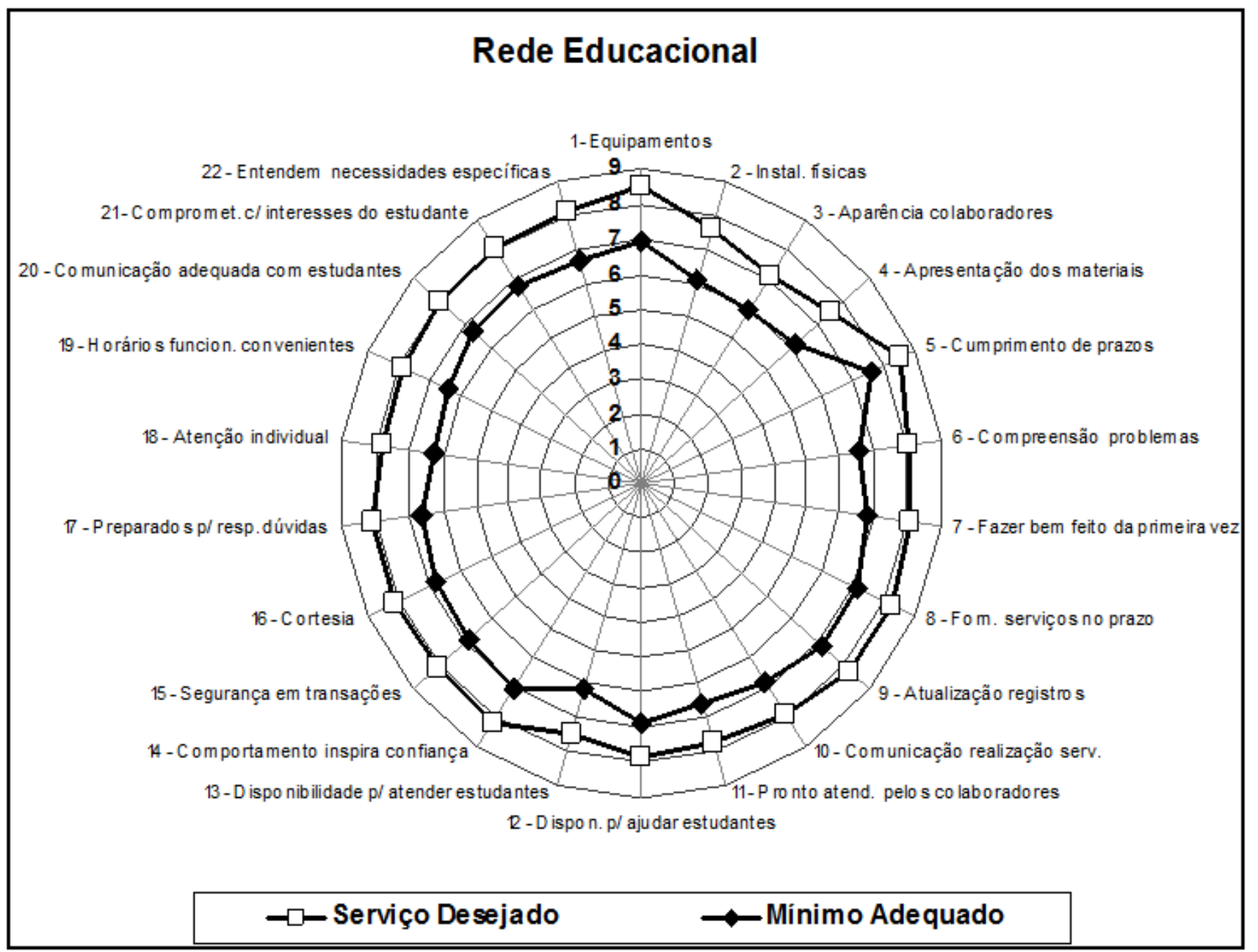

Figura 1: Análise entre o serviço mínimo desejado e percebido

Evidencia-se que, o movimento entre a percepção e o desejo dos estudantes acerca dos serviços educacionais em uma perspectiva de referendar um mínimo que sugerisse ser adequado a estes serviços.

Esta perspectiva de avaliação foi apresentada em ambos os formulários, para que se pudesse verificar se há uma oscilação na avaliação quando atribuídos o mínimo a partir das diferentes perspectivas, tanto para o serviço desejado quanto para o percebido. Esta variação na avaliaçáo realmente de tendenciosidades ao determinar um mínimo adequado, quando da perspectiva do serviço desejado, tanto quanto para o serviço percebido, a ponto de ser positiva e negativa dependendo da questáo, quando em tese deveriam ser iguais.

Outra forma de representar a avaliação dos serviços educacionais é verificando os movimentos ou oscilaçóes entre a diferença do serviço desejado e do serviço percebido. Sendo que um dos principais objetivos da metodologia é a avaliação do GAP do serviço, ilustrado na Figura 1. GAP 1 
ou Lacuna do serviço é apresentada na Figura 2, em que é possível observar os movimentos entre a expectativa e a percepção dos serviços educacionais prestados pelas IES da Rede.

É curioso verificar os movimentos gerados pelo gráfico na Figura 2, pois é possível verificar onde as diferenças na avaliação são mais ou menos intensas, como no caso da questão 3, que questiona sobre a apresentaçáo ou aparência dos colaboradores e professores.

O GAP ou lacuna apresenta-se negativa, podendo representar uma excelência neste quesito, o grau de importância exposto pelos estudantes no serviço desejado é inferior ao serviço percebido, ou seja, na percepçáo dos estudantes este item apresenta-se acima das expectativas dos estudantes. que investiga sobre o comprometimento da escola no cumprimento de prazos, obtendo na avaliação dos estudantes maior expectativa.

Quanto a percepção na execução dos serviços educacionais da rede, levando em consideração estas mesmas questóes, observa-se que estas tiveram uma avaliação baixa, entretanto, não foram as mais baixas registradas, totalizando uma média de 7,12 para a questáo 1 e de 6,91 para a questão 5 .

As médias mais baixas para os serviços prestados na avaliação da percepção dos estudantes, foram identificadas nas questóes 6 e 7 com médias 6,59 e 6,60 respectivamente, estas questóes tratam da compreensão por parte das escolas sobre os problemas dos alunos (questáo 6) e fazer bem feito as coisas na primeira vez (questão 7).

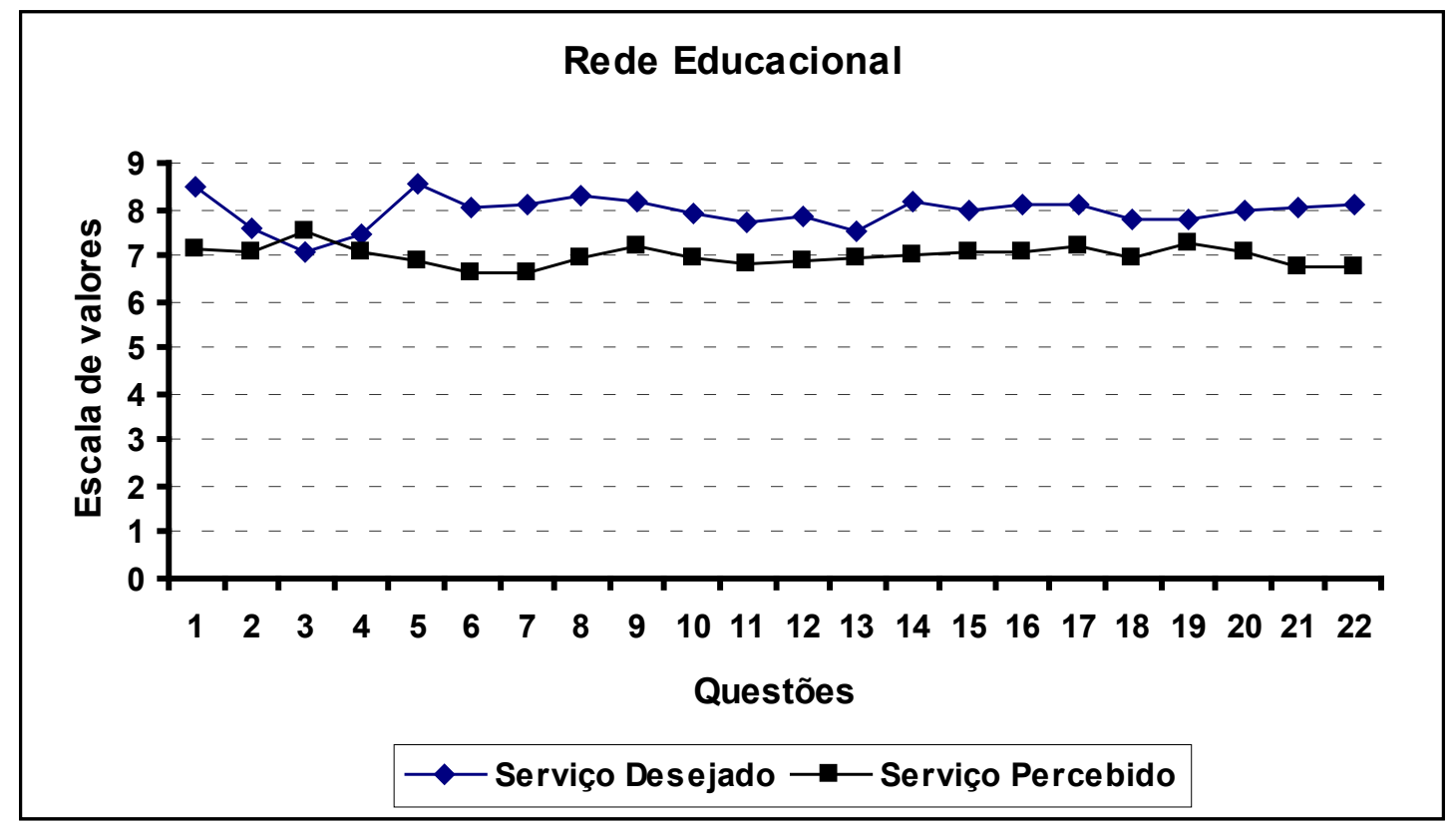

Figura 2: Análise da expectativa e percepção na Rede Educacional

Evidentemente, observando apenas a diferença entre a percepçáo e a expectativa dos estudantes, tem-se esta avaliação, mas além desta é preciso verificar cada questão isoladamente, e a Figura 2 auxilia significativamente para isto. A partir desta é possível observar a importância dada a cada questão, de acordo com a Figura observa-se que dentre todas as questóes, a de número 3 é a que possui menor relevância na percepção dos estudantes.

Por outro lado, as questóes que geram maior expectativa são: questão 1, que investiga sobre equipamentos e laboratórios, e a questão 5
Outros aspectos que podem ser identificados é o GAP ou Lacuna do serviço, de forma isolada. Este método pode auxiliar na identificação dos pontos críticos, bem como na avaliação de cada dimensão. Portanto, é possível tratar-se dos problemas mais aparentes questão à questão, ou abordar as dimensóes com maiores GAP's e suas questôes agrupadas, e ainda de forma mista, tratando da dimensão mais crítica de forma genérica e de questóes mais críticas de forma específica, a partir de um critério que cada organização poderá adotar individualmente. 
Para efeito deste trabalho optou-se por utilizar a média aritmética, para identificar um ponto médio de abordagem, entretanto, este método pode distorcer a avaliação, caso um único item tenha uma média muito superior às demais, elevando o desvio padráo para mais ou para menos.

A importância da Figura 3 se dá no momento que é permitido visualizar de forma rápida onde estáo os pontos críticos a serem atacados, observa-se a diferença entre os GAP's, obtidos questão à questão e a média obtida entre eles, ilustrada pela linha em cor "rosa", de acordo com a legenda. na Tabela 1, observa-se que estas questóes estão relacionadas a uma única dimensão da qualidade, a dimensão da "confiabilidade" que obteve uma média dos GAP's de 1,37 que pode ser considerada um tanto alta, visto que a média geral ficou em 0,95 .

Esta avaliação diz respeito aos serviços prestados pelas cinco Instituições de Ensino Superior, IES de uma Rede Educacional, localizadas no Rio Grande do Sul, que segundo bibliografia consultada diz respeito à capacidade de realizar um serviço prometido de forma eficaz e segura, e neste aspecto as IES como um todo, apresentam pontos críticos que requerem melhorias.

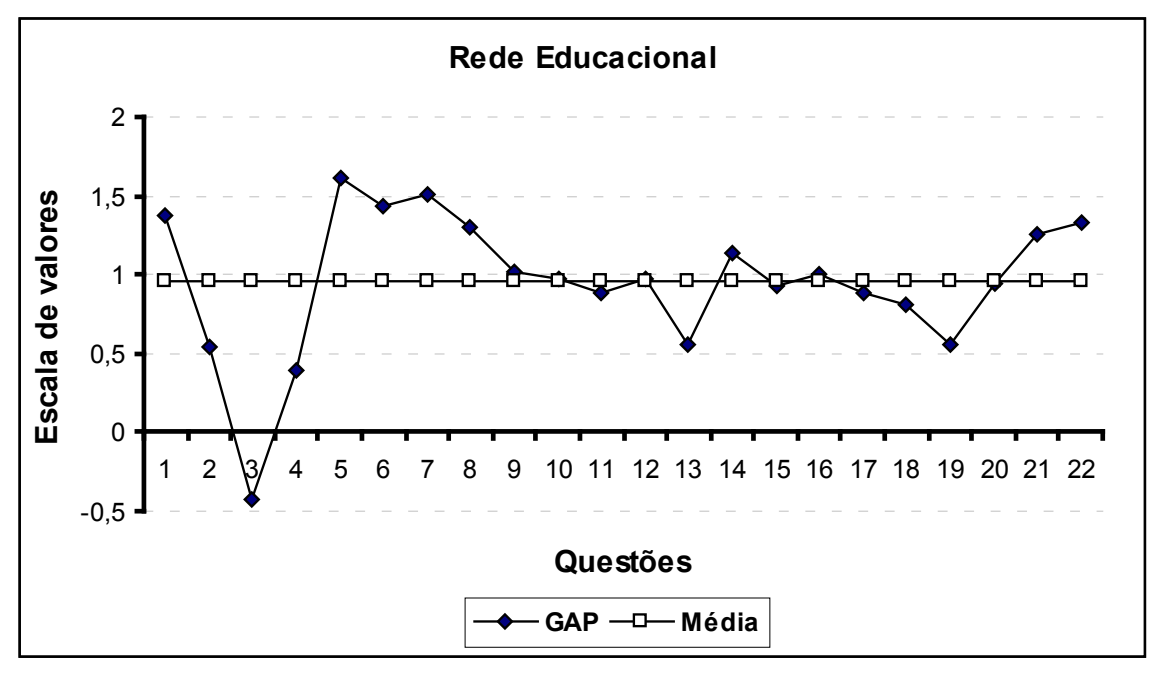

Figura 3: GAP entre o Serviço Desejado e Serviço Percebido

Uma das formas de tratar estas informaçóes pode ser: de que todas as questóes apresentadas com GAP's superiores a média merecem maior atenção e devem ser tomadas açóes relativas às expectativas dos estudantes.

Neste sentido na Rede Educacional, tem-se as questóes 1 (Equipamentos), 5 (Cumprimento de prazos), 6 (Compreensão de problemas), 7 (Fazer bem feito da primeira vez), 8 (Fornecimento de serviços no prazo), 9 (Atualização de registros), 10 (Comunicação da realização dos serviços), 12 (Disponibilidade para ajudar os estudantes), 14 (Comportamento inspira confiança), 16 (Cortesia), 21 (Comprometimento com os interesses do estudante) e 22 (Entendem as necessidades específicas), com indicadores acima da média.

Entretanto os pontos mais críticos conforme indica a Figura 3, apresenta uma sequência nas questóes $5,6,7$ e 8 . Ao observar os valores

\section{CONCLUSÓES}

A diversidade no conhecimento, a pesquisa por diferentes áreas do saber, sem qualquer intencionalidade, oferece respostas que muitas vezes parecem ser impossíveis de serem encontradas.

$\mathrm{Na}$ área de Marketing de Serviços, mais especificamente de Qualidade em Serviços, encontra-se a ferramenta (SERVQUAL) demonstrando ser a mais adequada e qualificada para preencher a lacuna que se abria, para identificar percepçóes e expectativas no gerenciamento do relacionamento com o cliente de serviços educacionais.

A adoção da ferramenta SERVQUAL, bem como da metodologia de aplicaçáo por meio da definição das Dimensóes da Qualidade em Serviços, possibilitou a realização da pesquisa, definindo a partir destas dimensóes, os motivos de maior insatisfação e satisfação dos estudantes matricula- 
dos nas Instituições de Ensino de uma Rede de Educação localizada no RS.

O diagnóstico proporcionou a análise dos resultados da pesquisa possibilitando a definição de fatores de competitividade que envolve todas as áreas de uma instituição agrupadas pelas dimensóes da qualidade, bem como, e por consequência da Rede Educacional.

A partir das pesquisas realizadas neste trabalho, foi possível analisar quais os aspectos que necessitam maior atenção por parte dos gestores, principalmente aqueles sinalizados pelos maiores $G A P$ 's, tal como, dissonância na percepção entre gestores e estudantes.

As principais dissonâncias apresentadas ou diagnosticadas no confronto das percepções com as expectativas dos estudantes da Rede, dizem respeito a duas dimensóes da qualidade, a dimensão dos Tangíveis, mas na avaliação destes não é a dimensão que demanda de maior atenção, não fosse uma única questão, a primeira, relativa aos serviços de laboratórios, bibliotecas e materiais didáticos, que obtiveram maiores $G A P$ 's apontados, provavelmente esta dimensão resultaria em valores negativos, ou seja, indicando superação das expectativas.

É preciso considerar também que, nesta dimensão, alguns pontos, não foram considerados relevantes, como por exemplo, a apresentação pessoal de funcionários e professores, não convém, no entanto, simplesmente desconsiderar este aspecto, pois náo apresentou importância comparativamente aos demais. $\mathrm{O}$ abandono deste ponto poderá ser considerado como desleixo em uma próxima avaliação.

O segundo ponto de divergência foi apontado com muita intensidade, na dimensão "Confiabilidade". Este inclusive é um ponto crítico que deve ser encarado como prioritário pelas IES, pois foi apontado como a dimensão que possui maior índice de insatisfação na percepção dos estudantes, com uma intensidade similar as dimensôes da "Segurança" e "Empatia", representado pela percepçáo dos gestores que talvez estivessem próximos a alcançar as expectativas dos serviços nesta dimensão.

$\mathrm{Na}$ dimensão "Confiabilidade", já relatado tem a pretensão de avaliar se o serviço prometido é realizado de forma confiável e precisa. Independentemente da Instituição, todas obtiveram nesta dimensão o seu maior GAP.
As questôes relacionadas a esta dimensão, dizem respeito à insatisfaçáo no cumprimento de prazos e foi a questão que obteve maior GAP praticamente em todas instituiçóes.

Os principais pontos a serem atacados momentaneamente pelas IES, como pontos críticos e que talvez contribuam de forma negativa, mas que, se atacada corretamente, revertendo a percepção desta dimensão poderá transformar-se, passando da condição de um problema à condição de vantagem competitiva.

Evidentemente a ferramenta não identifica somente problemas, identifica sim os fatores positivos que podem servir de estratégia para o fortalecimento das relaçóes com o mercado e principalmente com seus clientes.

Em relação à dimensão que pudesse ser considerada como uma vantagem competitiva seria a dimensão da "Responsividade" que propóe identificar a capacidade da IES em ajudar o estudante e sua disponibilidade em atendê-lo.

A questão que, melhor representa isto, se relaciona ao fato de professores e funcionários não estarem ocupados demais para destinar-lhes atenção. Este ponto foi considerado como o ponto mais positivo pelos estudantes.

Atualmente com o advento da crescente evoluçấo da tecnologia da informação e das ferramentas tecnológicas, vive-se um período de crise de atenção, motivados pelos relacionamentos virtuais, facilidade de comunicação promovida pela tecnologia, informática, telefonia móvel entre outros benefícios.

Neste sentido seria prudente elaborar uma nova pesquisa, para identificar se esta vantagem competitiva apontada nas IES é motivada pela facilidade de acesso, presteza e relacionamento pessoal com professores e funcionários, ou se pela agilidade, mobilidade e facilidade de localização oferecida pela tecnologia de comunicação.

Diante do exposto e pela necessidade de apontar como os objetivos propostos pelo presente trabalho, foram atingidos apresentam-se de forma sintética as evidências anteriormente relatadas. A partir da análise dos objetivos identificou-se o seguinte:

A prioridade estratégica da Rede identificada por meio das percepçóes dos estudantes está na dimensão "Confiabilidade". Os critérios para conversão das dimensôes da qualidade em serviços em fatores de vantagem competitiva devem ser di- 
retamente proporcionais ao resultado dos Gap's mensurados, tanto positivos quanto negativos.

Para efeitos conclusivos seria possível afirmar que as vantagens competitivas das Instituiçóes de Ensino Superior da Rede Educacional estudada estariam assim distribuídas: Rede (Geral): instalações físicas atraentes; material gráfico, murais e indicativos visualmente atraentes; disponibilidade em atender e responder às solicitaçôes; e horários de funcionamento convenientes.

\section{REFERÊNCIAS}

AHMED, Z.; Shoeb, Z.H. Measuring service quality of a Public University Library in Bangladesh Using SERVQUAL. Performance measurement and metrics, v. 10, n. 1, p. 17-32, 2009.

AZEVEDO, R.C.; BREMER, C.F.; REBELATTO, D.A.N.; TARALLO, F.B. O uso de ERP e CRM no suporte à gestáo da demanda em ambientes de produção Make-to-Stock. Gestão e Produção. Vol.13, n.2, p. 179-190, 2006.

BABAKUS, E.; MANGOLD, W.G. Adapting the SERVQUAL scale to hospital services: an empirical investigation. Health Services Research, v. 26, n. 6, p. 767-86, 1992.

BLACKWELL, R.D; MINIARD, P.W.; ENGEL, J.F. Comportamento do Consumidor. 9.ed. Sao Paulo: Pioneira Jhomson Learning, 2005.

BLERY, E.K.; MICHALAKOPOULOS, M. G. An e-CRM application in the telecommunications sector: A case study from Greece. EuroMed Journal of Business, Vol. 1 n. 2, p. 5-14, 2006.

BRETZKE, M. Marketing de Relacionamento e Competição em Tempo Real com CRM. São Paulo: Atlas, 2000.

BRYSON, J.R. Hybrid Manufacturing Systems and Hybrid Products: Services, Production and Industrialisation. Aachen \& LuLu-Verlag, Auflage. 2010.

BUTT, M.M.; RUN, E.C. Private healthcare quality: applying a SERVQUAL model. International Journal of Health Care Quality Assurance, v. 23, n. 7, p. 658-673, 2010.

CHURCHILL J.R., GIBLBERT A. Marketing: Criando Valor Para Os Clientes. São Paulo: Saraiva, 2000.

COBRA, M.; BRAGA, R.. Marketing Educacional. São Paulo: Cobra Editora, 2004.
CRONBACH, L. Essentials of psychological testing. $3^{\mathrm{a}}$ ed. New York: Harper and Row, 1990.

GIANESI, I.G.N.; CORRÊA, H.L. Administração estratégica de serviços: operaçóes para satisfação do cliente. 6.ed. São Paulo: Atlas, 1996.

KIMILOGLU, H.; ZARALI, H. What signifies success in e-CRM?. Marketing Intelligence \& Planning, Vol. 27, n. 2, p. 246-267, 2009.

KOTLER, P.; FOX, K.F.A. Marketing Estratégico Para Instituiçóes Educacionais. São Paulo: Atlas, 1994.

LAI, F.; HUTCHINSON, J.; LI, D.; BAI, C. An empirical assessment and application of SERVQUAL in mainland China's mobile communications industry. International Journal of Quality \& Reliability Management, v. 24, n. 3, p. 244-262, 2007.

LOVE, J.H.; ROPER, S.; BRYSON, J.R. Openness, knowledge, innovation and growth in UK business services. Research Policy Journal.

NEWMAN, K. Interrogating SERVQUAL: a critical assessment of service quality measurement in a high street retail bank. International Journal of Bank Marketing, v. 19, n. 3, p. 126-139, 2001. PARASURAMAN, A.; ZEITHAML, V.A.; BERRY, L.. Delivering Quality Service: Balancing Perceptions and Expectations. New York: The Free Press, 1990.

PARASURAMAN, A.; ZEITHAML, V.A.; BERRY, L. Marketing Services: Competing Through Quality, New York: The Free Press, 1991.

PLATA, S. De acordo com a vontade do cliente. 2003. Disponível em: <http://www.Intermanagers.com.br>. Acesso em: 15 julho. 2011.

STEFANO, N. Uma avaliação empírica e aplicação da escala SERVQUAL e do Índice PASC para a mensuração da qualidade dos serviços. Revista de Economia e Administração, v. 8, p. 181-196, 2009. SWIFT, R. Customer Relationship Management (CRM): o revolucionário marketing de relacionamentos com os clientes. Traduçáo Flávio Deny Steffen. Rio de Janeiro: Campos, 2001.

VANDERMERWE, S. From Tim Soldiers to Russian Dolls: Creating Added Value Through Services. Butterworth-Heinemann, Oxford, 1993.

WHITELEY, R.C. A Empresa Totalmente Voltada Para o Cliente: The Customer Driven Company. 16. ed. Rio de Janeiro: Campus, 1992. 